\title{
Motivation and Job Burnout: The Mediating Role of Organizational Citizenship Behavior
}

\author{
Meily Margaretha \\ Maranatha Christian University, Bandung, Indonesia
}

\begin{abstract}
The occurrence of a change in work motivation and loss of enthusiasm was experienced by workers associated with excessive stress or disappointment experienced in work situations. Workers with more intrinsic and extrinsic motivations are likely to experience less burnout. This study aimed to examine and analyze whether intrinsic and extrinsic motivations significantly influence job burnout. Additionally, this research investigated the individual factors associated with the effects of intrinsic/extrinsic motivation on burnout; specifically, it explored the mediating role of organizational citizenship behavior (OCB) in the relationship of employees' job motivation with burnout. Data were collected from 97 employees from several private clinics in Jakarta, Indonesia, through questionnaires. The result of the study found that motivation (intrinsic and extrinsic) has a significant effect on job burnout. Lastly, OCB had a mediating effect on the relationship between intrinsic motivation and job burnout. The results of the study provide valuable insights into the effects of motivation on job burnout. Managerial implications exist, as managers could balance the fulfillment of employee needs that would trigger the emergence of intrinsic and extrinsic motivation; hence, it is expected to prevent the occurrence of the desire of job burnout on employees.
\end{abstract}

Keywords: Intrinsic Motivation, Extrinsic Motivation, Job Burnout, Organizational Citizenship Behavior

\section{Introduction}

Employee motivation is shown through energy directed towards work attitudes to achieve the goals of the organization (Salami, 2008 in Karabay et al., 2014; Eymur \& Geban, 2011 in Karabay et al., 2014). McClelland (in Primita \& Wulandari, 2014) explains that individuals who have high achievement motivation will have a sense of responsibility and high self-esteem, are more resilient, more active and having a desire in carrying out and complete their tasks very well. On the other hand, there is a change in work motivation and loss of enthusiasm experienced by workers associated with excessive stress or disappointment experienced in work situations (Maslach, 1981 in Tawale et al., 2011).

Responses to crisis emotional stress characterized by emotional or physical fatigue, decreased productivity, excessive depersonalization, defined as job burnout (Perlman \& Hartman, in Kristiana et al., 2016). Job burnout is a comprehensive concept, first proposed by Freudenberger in clinical psychology in 1974 (in Zhang \& Feng, 2011). Maslach and Jackson (in Kristiana et al., 2016) state that job burnout consists of the following three dimensions: emotional exhaustion, depersonalization, and reduced personal accomplishment.

Mulyana (in Sukmana \& Sudibia, 2015) explains that job burnout can occur due to monotonous or non-varied work, vague work tasks, poor work control, dysfunctional work environment, and extreme activities. Moreover, the discrepancies given by the company to employees, such as the existence of unhealthy competition among fellow employees, lack of support from superiors, will create the symptoms of burnout of employees (Harry \& Yanuar, 2010 in Sukmana \& Sudibia, 2015). Chernis (in Limonu, 2013) also added other factors that cause burnout jobs such as the leadership style applied by superiors, lack of social support given by family, co-workers, or superiors. The symptoms of burnout job that occur in employees characterized by physical, mental, and emotional fatigue, also low self-esteem (George \& Jones, 2005 in Tawale et al., 2011). Furthermore, the organizational environment has drastically changed in recent years; employees become more stressed about the possibility of losing their tenure, seniority-based salary, and stable organizational culture. Organizational environmental changes tend to make employees dissatisfied and emotionally frustrated with their work conditions. 
Several empirical studies have found the relationship between motivation and burnout. The study of Zhang, Liu, and Yuan (2009) found that learning goal orientation and intrinsic work motivation significantly predicted job burnout of employees in each dimension. Qureshi (2013) found that relationship of all dimensions of work motivation with the dimensions of burnout and intention to leave of top-level manager from the garment industry in India. Furthermore, research conducted by Tawale et al. (2011) on nurses at Papua-Indonesia obtained the same results that nurses' work motivation had a negative relationship with the tendency to experience burnout. Lyndon et al. (2017), in their research, found that burnout and quality of life of medical students in New Zealand have a relationship with academic motivation and achievement. Moreover, previous research conducted by Kim (2018) found that intrinsic and extrinsic motivation had a significant effect on burnout and turnover intention.

This research focused on the motivation and job burnout among employee from several private clinics in Jakarta, Indonesia, more specifically focused on employees' intrinsic and extrinsic motivations as job factors to burnout. Additionally, this research investigated the individual factors associated with the effects of intrinsic/extrinsic motivation on burnout; specifically, it explored the mediating role of organizational citizenship behavior (OCB) in the relationship of employees' job motivation with burnout.

\section{Literature Review}

\section{The Relationship between Intrinsic and Extrinsic Motivation with Job Burnout}

Job burnout defined as a form of psychological tension or pressure associated with chronic stress, experienced by someone from day to day characterized by physical, mental, and emotional fatigue according to Pines and Aronson (Tawale et al., 2011). The occurrence of a change in work motivation and loss of enthusiasm experienced by workers associated with excessive stress or disappointment experienced in work situations (Maslach, 1981 in Tawale et al., 2011). Maslach (1978, in Ducharme, 2008) stated that employees' burnout due to intensive interpersonal interactions, should carefully address because it could harm employees' physical and mental health as well as work performance.

When employees experience job burnout, employees can lose motivation for achievement (Mondy, 2016). According to the theory of self-determination, intrinsic, and extrinsic motivation can be related to job burnout (Kim, 2018). The theory of self-determination emphasizes the importance of the core of human resources that evolved for personality development and self-regulation, which distinguishes between intrinsic and extrinsic motivation (Ryan \& Deci, 2000a). Ryan and Deci (2000a) also state that the theory of self-determination shows the adverse effects of extrinsic motivation on burnout jobs weaker than intrinsic motivation, this is because employee extrinsic motivation controlled by external factors and employees are less willing to behave spontaneously due to lack of autonomy work. Low motivation in self-determination is positively related to job burnout (Cresswell \& Eklund, 2005). In Kim's (2018) study, it found that intrinsic motivation had a significant adverse effect on job burnout, and extrinsic motivation had a significant positive effect on job burnout. In the research Cresswell \& Eklund (2005) also found that intrinsic motivation was consistent and strongly associated with job burnout. Other research by Low, et al. (in Karambay et al., 2014) who investigated the relationship between burnout, attitudes, and behavior using the results of a survey of sellers in Australia found that intrinsic motivation, role ambiguity, and role conflict had a significant effect on job burnout. Job burnout is another factor that influences employee attitudes and behaviors that reduce motivation as a result of reactions to work stress (Keel, 1993 in Karabay et al., 2014). Spickard (in Primita \& Wulandari, 2014) conducted a study of working medical students and found that job burnout had a negative relationship to personal achievement and academic achievement motivation. Furthermore, research conducted by Tawale et al. (2011) on nurses at Papua Hospital in Indonesia showed the same results that nurses' work motivation had a negative relationship with the tendency to experience job burnout.

Moreover, research conducted by Primita and Wulandari (2014) on badminton athletes in Indonesia showed that achievement motivation had a negative relationship with burnout. Based on the above explanation regarding the views and previous research on the effect of motivation and job burnout, the hypothesis proposed is as follows:

H1: There is an influence of motivation (intrinsic and extrinsic) on job burnout

\section{The Mediating Effect of OCB on the Relationship between Motivation and Job Burnout}

Organizational citizenship behavior (OCB) defined as organizational members' voluntary efforts to achieve organizational effectiveness, and it consists of altruism, courtesy, sportsmanship, civic virtue and conscientiousness (Niehoff \& Moorman, 1993). Employees' individual characteristics, such as OCB are significantly associated with the relationship between motivation and burnout (Kim, 2018). According to social exchange theory (Cropanzano et al., 2003), employees tend to form a relationship of social exchange to the extent that valuable benefits are given to them. 
The theory explains why employees who are motivated by intrinsic and extrinsic benefits form social exchange relationship with their organization. Therefore, intrinsically and extrinsically motivated employees are more likely to willing to serve their organization and customers. That is, intrinsic and extrinsic motivations will positively influence OCB.

Employees with high levels of OCB are inclined to respond positively to the tasks rather than the mandatory ones. In the same vein, employees with high levels of OCB tend to cope actively with their works, and they tend to be less emotionally exhausted and less likely to depersonalize others due to their job satisfaction and psychological stability. Therefore, the second hypothesis proposed is as follows:

$\mathrm{H} 2$ : OCB will significantly mediate the relationship intrinsic/extrinsic motivation with job burnout

The research model used in this study is depicted in Figure 1.

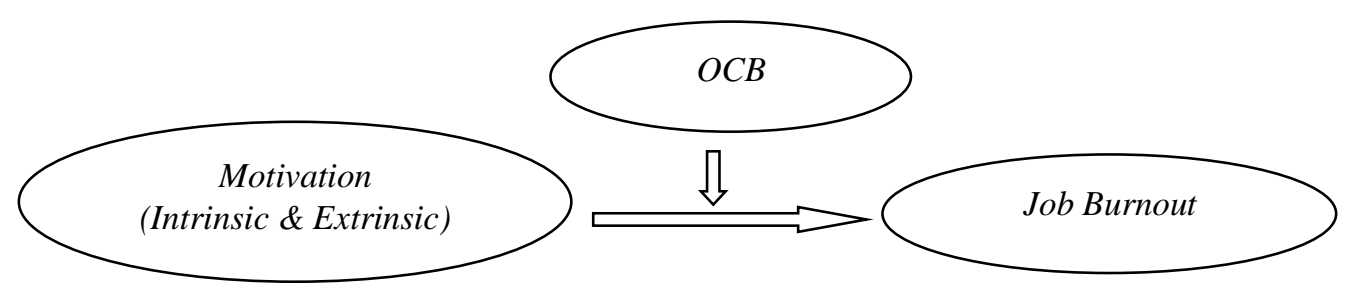

Figure 1. Research Model

\section{Methodology}

The sample in this study was 97 employees from several private clinics in the city of Jakarta in Indonesia. Data collected through questionnaires distributed through direct surveys. The research instrument used Likert's five-point scale. The intrinsic and extrinsic motivation measured by instruments developed by Ryan and Deci (2000b). Job burnout measured according to Maslach Burnout Inventory by Maslach and Jackson (1981, in Kim, 2018) as well as approaches used by Hsieh (2014). Organizational Citizenship Behavior as the intervening variable measured with the items adopted by Niehoff and Moorman (1993). The collected data analyzed by testing the validity and reliability, and the hypotheses tested with regression analysis that used to test the relationship and influence between independents, dependent, and mediating variables.

\section{Result and discussion}

The demographic information (Table 1) provides general information about respondents on gender, age, and level of education. Table 1 enables us to get a better understanding of the type of respondents. As table 1 exhibit, our respondents consist of (24.7\%) men and (75.3\%) for women. The majority of the respondents hold a bachelor's degree $(50.5 \%)$ with age ranging $25-31$ years $(41.2 \%)$ and with years of work between $1-3$ years.

This study used a questionnaire developed from previous research and translated into Bahasa Indonesia to be easily understood by the respondents. Testing of construct validity was done by using factor analysis with orthogonal technique and varimax rotation. Confirmatory factor analysis used in this study by the underlying theories. Hair et al. (2006) suggested that factor loading above 0.40 proved that the constructs are valid in practically significant. The result of construct validity test with factor analysis showed that the loading factor of question items was between 0.411 and 0.763. Question items that have a factor loading less than 0.4 discarded.

Reliability testing was done by measuring internal consistency with Cronbach alpha. The internal consistency of motivation items assessed by computing the total reliability scale; the reliability scale for the study is $(0.857)$. This reliability value for job burnout is (0.877) and for organizational citizenship behavior is (0.808). Table 2 describes the factor loading and Cronbach alpha for each construct or variables used in this study. According to Zikmund, Babin, Carr, and Griffin (2010), reliability less than 0.6 is not adequate, 0.7 is acceptable, and over 0.8 is good. According to Zikmund et al. (2010), all constructs in this study declared reliable. Table 1 describes the factor loading and Cronbach alpha for each construct or variables used in this study. 
Meily Margaretha

Motivation and Job Burnout: The Mediating role of Organizational Citizenship Behaviour

Table 1. Demographic Description

\begin{tabular}{ccc}
\hline Characteristics & Values & $\begin{array}{c}\text { \% Frequency For } \\
\text { Employees }\end{array}$ \\
\hline Gender & Men & 24,7 \\
& Women & 75,3 \\
Age & $18-24$ years & 33,0 \\
& $25-31$ years & 41,2 \\
& $32-38$ years & 14,4 \\
Level of Education & $39-45$ years & 7,2 \\
& Above 45 years & 4,1 \\
Tenure & High School & 49,5 \\
& Graduate & 50.5 \\
& Below 1 year & 30,9 \\
& $1-3$ year & 32,0 \\
& $4-6$ years & 18,6 \\
& 7 - 9 years & 9,3 \\
& Above 10 years & 9,3 \\
\hline
\end{tabular}

Sources: Primary Data, processed.

Table 2. Valid and reliable questionnaires, factor loading, and Cronbach alpha.

\begin{tabular}{|c|c|c|}
\hline QUESTIONNAIRES & $\begin{array}{l}\text { JOB } \\
\text { BURNOUT }\end{array}$ & $\begin{array}{l}\text { INTRINSIC \& } \\
\text { EXTRINSIC } \\
\text { MOTIVATION }\end{array}$ \\
\hline Intrinsic Motivation1 & & 0,724 \\
\hline Intrinsic Motivation2 & & 0,709 \\
\hline Intrinsic Motivation3 & & 0,763 \\
\hline Intrinsic Motivation4 & & 0,682 \\
\hline Intrinsic Motivation5 & & 0,468 \\
\hline Extrinsic Motivation1 & & 0,737 \\
\hline Extrinsic Motivation2 & & 0,699 \\
\hline Extrinsic Motivation3 & & 0,747 \\
\hline Extrinsic Motivation4 & & 0,459 \\
\hline Extrinsic Motivation5 & & 0,619 \\
\hline Job Burnout1 & 0,725 & \\
\hline Job Burnout2 & 0,509 & \\
\hline Job Burnout3 & 0,462 & \\
\hline Job Burnout4 & 0,575 & \\
\hline Job Burnout5 & 0,478 & \\
\hline Job Burnout6 & 0,617 & \\
\hline Job Burnout7 & 0,641 & \\
\hline Job Burnout8 & 0,616 & \\
\hline Job Burnout9 & 0,567 & \\
\hline Job Burnout18 & 0,464 & \\
\hline
\end{tabular}




$\begin{array}{cc}\text { Job Burnout19 } & 0,506 \\ \text { Job Burnout20 } & 0,661 \\ \text { Job Burnout21 } & 0,411 \\ \text { Job Burnout22 } & 0,497\end{array}$

OCB1

OCB2

\section{Motivation and Job Burnout}

This first hypothesis in this study examined the effect of motivation (intrinsic/extrinsic) on job burnout. As a result it was found that intrinsic and extrinsic motivation had a significant effect on work saturation with a significant value of 0.001 and $\mathrm{R}$ Square values of 0.103 or $10.3 \%$, it was indicated that intrinsic and extrinsic motivation effect job burnout by $10.3 \%$ while $89.7 \%$ is explained by other reasons outside of this research model (see Table 3). Therefore, the results of this study supported several previous studies such as Kim's (2018) study stated that intrinsic motivation has a significant negative effect on burnout job and extrinsic motivation has a significant positive effect on burnout job. The study of Zhang, Liu, \& Yuan (2009) also found that learning goal orientation and intrinsic work motivation significantly predict job burnout of employees in each dimension.

Furthermore, the research of Cresswell and Eklund (2005) found that low motivation in self-determination positively related to job burnout and intrinsic motivation negatively related to job burnout. When employees experience job burnout, employees can lose motivation for achievement (Mondy, 2016). However, when it examined partially, only intrinsic motivation was significantly and negatively associated with job burnout, in contrast, extrinsic motivation had no significant relations with employees' job burnout. Intrinsically motivated employee experienced lower job burnout compared to extrinsically motivated employees.

\section{The Mediating Effect of OCB on the Relationship between Motivation and Job Burnout}

The second hypothesis stated that OCB significantly mediates the relationship between intrinsic/extrinsic motivation and job burnout. Based on the result of the study, it was found that OCB had a significant mediating effect on the relationship between intrinsic motivation and job burnout (Standardized $\beta=-0.400, \rho<0.005$ ). Therefore, the negative relationship between intrinsic motivation and job burnout reduced when controlled for OCB. Employees with more intrinsic motivation are more likely to engage in OCB more easily; thus, H2 partially supported. The result of the study 
supported the research conducted by Kim (2018) found that organizational citizenship behavior and public service motivation had a significant mediating effect on the relationship between intrinsic motivation and employees' burnout.

Table 3. Summary of the Hypothesis

\begin{tabular}{|c|c|c|c|c|}
\hline Variables & $R^{2}$ & $\begin{array}{c}\text { Unstandardized } \\
B\end{array}$ & $\begin{array}{c}\text { Standardized } \\
\text { Coefficients Beta }\end{array}$ & Sig. \\
\hline $\begin{array}{c}\text { Motivation (Intrinsic \& Extrinsic) } \rightarrow \\
\text { Job Burnout }\end{array}$ & .103 & -.407 & -.320 & .001 \\
\hline Intrinsic Motivation $\rightarrow$ Job Burnout & .144 & -.870 & -.380 & .000 \\
\hline Extrinsic Motivation $\rightarrow$ Job Burnout & 0.036 & -.418 & -.190 & .062 \\
\hline $\begin{array}{c}\text { Intrinsic Motivation } \rightarrow O C B \rightarrow \mathrm{Oob} \\
\text { Burnout }\end{array}$ & 0.148 & -.916 & -.400 & .004 \\
\hline $\begin{array}{c}\text { Extrinsic Motivation } \rightarrow O C B \rightarrow \mathrm{Job} \\
\text { Burnout }\end{array}$ & 0.038 & -.0042 & -.0042 & .680 \\
\hline
\end{tabular}

Sources: Primary Data, processed.

\section{Conclusion}

This study investigated the effect of motivation (intrinsic and extrinsic) on job burnout. The first hypothesis was supported; however, when it was examined partially, only intrinsic motivation was found to be significantly related to job burnout. The effect of intrinsic motivation was consistent with the researcher expectations, but the effect of extrinsic motivation was not as expected. It concluded that an increase in intrinsic rather than extrinsic motivation reduced employees' experience of job burnout. Intrinsically motivated employees who driven by enjoyment and interest are more likely to work hard at their jobs, less emotional exhaustion, and increase the desire to participate in the organization. Meanwhile, although employees with more intrinsic motivation are likely to reduce their own experience of burnout, it was found that OCB indirectly influenced the relation between their intrinsic motivation and job burnout. When employees maintained sufficient OCB, they were likely to experience less job burnout. Employees with OCB work readily and voluntarily due to increased competence and autonomy.

Based on the study, it is essential to support employees who experience job burnout and provide them with relevant education to enhance OCB. The leaders in the organization should develop proper strategies to help employees who are experiencing a high level of stress associated with customers' complaints. According to Hsieh (2014), the organization should help employees who are at an increased risk of burnout to reduce their emotional stress by training them to handle job-related emotions and providing with helpful resources such as psychological counseling.

\section{References}

- Cresswell, S. L.\& Eklund, R. C. (2005). Motivation and Burnout in Professional Rugby Players. Research Quarterly for Exercise and Sport, pp. 370-376.

- Cropanzano, R.., Rupp, D. E., \& Byrne, Z. S. (2003). The relationship of emotional exhaustion to work attitudes, job performance, and organizational citizenship behaviors. Journal of Applied Psychology, Vol. 88 No. 1, pp. 160-169.

- Hair, J. E., Black, W. C., Babin, B. J., Anderson, R. E., \& Tatham, R. L. (2006). Multivariate data analysis (6th ed.). Upper Saddle River, NJ: Prentice-Hall International.

- Hsieh, C. (2014). Burnout among public service workers: the role of emotional labor requirements and job resources. Review of Public Personnel Administration, Vol. 34, No.4, pp. 379-402

- Limonu, F. (2013). The relationship work motivation on burnout of nurses in Local Public Hospital in Gorontalo, Indonesia. Thesis Undergraduate Unpublished from Gorontalo Public University

- Lyndon, M. P., Henning, M. A., Alyami, H., Krishna, S., Zeng, I., Yu, T. C., \& Hill, A. G. (2017). Burnout, quality of life, motivation, and academic achievement among medical students: A person-oriented approach. Perspect Med Educ, DOI 10.1007/s40037-017-0340-6

- Karabay, M. E., Tezergil, S. A.,\&Köse, A. (2014). Does Motivation Mediate the Job Performance and Burnout? Evidence from Turkish Banking Sector. American International Journal of Social Science.Vol. 3.No. 6, pp. 98-108. 
- Kim, J. (2018).The Contrary Effects of Intrinsic and Extrinsic Motivations on Burnout and Turnover Intention in The Public Sector. International Journal of Manpower.Vol. 39, pp. 486-500.

- Kristiana, B., Yusuf, M., \& Priyatama, A. N. (2016). The relationship between job insecurity, burnout and turnover intention. Candrajiwa Scientific Psychology Journal, Vol.4. No.4, pp.273-287

- Mondy, R. (2008). Human Resource Management. USA: Pearson Education

- Niehoff, B. P., \& Moorman, R. H. (1993). Justice as a mediator of the relationship between methods of monitoring and organizational citizenship behavior. Academy of Management Journal, Vol. 36 No. 3, pp. $527-$ 556.

- Primita, H. Y.\&Wulandari, D. A. (2014). The relationship between achievement motivation on burnout of badminton athletes in Purwokerto, Indonesia. Psycho Idea.No.1, pp. 10-18.

- Qureshi, S. (2013). The Relationship between Work Motivation, Burnout and Intention to Leave for the Top Level Managers of Garment Industry (A Case Study of Indian Garment Industry). International Journal of Human Resource Studies, Vol. 3, No. 4, pp. 128-142

- Ryan, R.M. \& Deci, E.L. (2000a): Self-determination theory and the facilitation of intrinsic motivation, social development, and well-being. American Psychologist, Vol. 55 No. 1, pp. 68-78.

- Ryan, R.M. \& Deci, E.L. (2000b): Intrinsic and extrinsic motivations: classic definitions and new directions. Contemporary Educational Psychology, Vol. 25 No. 1, pp. 54-67

- Sukmana, E. \&Sudibia, G. A. (2015). The effect of transformational leadership, motivation, and burnout on outsourcing employee performance of Radio Republic of Indonesia in Mataram, Indonesia. E-Management Journal Udayana University. Vol. 4. No. 8, pp. 1-17.

- Tawale, E. N., Budi, W.,\& Nurcholis, G. (2011). The relationship between work motivation on burnout of nurses in Local Public Hospital Serui-Papua. Insan. Vol. 13.No. 2, pp. 74-84.

- Zhang, K., Liu, Y.,\&Yuan, Y. (2009). Motivational Predictors of Job Burnout: Learning Goal Orientation and The Mediating Role of Intrinsic Work Motivation.International Conference on Bioinformatics and Biomedical Engineering, pp. 1-4.

- Zhang, Y.\& Feng, X. (2011). The Relationship between Job Satisfaction, Burnout, and Turnover Intention Among Physicians from Urban State-Owned Medical Institutions in Hubei, China: A Cross-Sectional Study.BMC Health Services Research, pp. 1-13.

- Zikmund, W. G., Babin, B. J., Carr, J. C., \& Griffin, M. (2010). Business research methods (8th ed.). Mason, $\mathrm{OH}$ : South-Western Cengage Learning. 